Short Communication

\title{
Electrocatalysis of $\mathrm{CO}_{2}$ Reduction on Nano Silver Cathode in Ionic Liquid BMIMBF 4 : Synthesis of Dimethylcarbonate
}

\author{
Yafeng Luo, Chuibo Xia, reyisha abulizi, Qiuju Feng ", Wenping Liu, Aihua Zhang, \\ College of Chemistry and Chemical Engineering, Jishou University, Jishou416000, China \\ *E-mail: fqj245@126.com
}

doi: $10.20964 / 2017.06 .67$

Received: 12 December 2016 / Accepted: 19 April 2017 / Published: 12 May 2017

\begin{abstract}
Nano silver particles deposited on conductive glass was prepared by cyclic voltammogram. This obtained electrode was used to catalyze electroreduction of carbon dioxide for synthesize dimethylcarbonate. Results show that the process of electrochemical reduction of $\mathrm{CO}_{2}$ on nano silver particles electrode in 1-butyl-3-methylimidazoliumtetrafluoborate $\left(\mathrm{BMIMBF}_{4}\right)$, is step by step, which is proved by two reduction peaks at $-1.8 \mathrm{~V}$ and $-2.2 \mathrm{~V}$ (vs. Ag). Under mild conditions, electrolyses experiments were carried out in an undivided cell at $-1.8 \mathrm{~V}$ without any toxic solvents, catalysts and supporting electrolytes, yielding the dimethyl carbonate with yield of $83 \%$. Moreover, no other product was found in liquid product.
\end{abstract}

Keywords: Electrocatalytic, Nano silver, $\mathrm{CO}_{2}$, Dimethylcarbonate, Ionic liquid

\section{$\underline{\text { FULL TEXT }}$}

(C) 2017 The Authors. Published by ESG (www.electrochemsci.org). This article is an open access article distributed under the terms and conditions of the Creative Commons Attribution license (http://creativecommons.org/licenses/by/4.0/). 